\title{
INVESTIGASI VARIASI KECEPATAN POTONG OPTIMAL PADA PROSES PEMESINAN BAJA AISI 4140
}

\author{
M. Sobron Y. Lubis, Rosehan dan Moses Kamillo Tjenardi \\ Program Studi Teknik Mesin Jurusan Teknologi Industri \\ Fakultas Teknik Universitas Tarumanagara \\ e-mail: sobronl@ft.untar.ac.id
}

\begin{abstract}
Determination of optimum cutting speed in the lathe process should be considered in order to produce minimal machining costs and maximum production. Research The determination of optimum cutting speed was done to investigate the effect of cutting speed when cutting AISI 4140 steel against cost and production obtained. This study was conducted experimentally using lathe and theoretical calculations to determine machining costs and the amount of production produced. The lathe process is carried out using carbide cutting tools for cutting of AISI 4140 steel metal. In this machining the data obtained is the cutting time of the machining process tail loading process then the data is incorporated into the equation together with the cutting force, the cost of the cutting tools, the workpiece, the cost labourers. Then from the calculation results obtained by graph machining cost and production amount. Based on the graph, it is observed minimal machining cost and maximum production amount to know the optimum cutting point. The results obtained.The increase in cutting rate gives effect to the increase of production quantity, while for calculation of machining cost has decreased. Machining time has a significant effect on the change of production quantity and machining cost. The optimal cutting speed $\left(V c_{\text {opt }}\right)$ is $269 \mathrm{~m} / \mathrm{min}$.
\end{abstract}

Keywords: production rate, optimization, operating modes, minimum cost.

\section{PENDAHULUAN}

Baja AISI 4140 atau JIS SCM440 yang merupakan baja paduan rendah yang dikenal mempunyai sifat tangguh yang biasa diaplikasikan dalam komponen transmisi roda gigi seperti pinion, sproket, tailstock, dan poros (shafts). Pemilihan jenis logam ini sesuai digunakan pada pembuatan komponen yang sudah disebutkan dikarenakan memiliki berberapa karakteristik seperti tahan aus (wear resistance), ketangguhan yang cukup tinggi, dan mudah dibentuk (machinability).

Pada proses pembubutan untuk menentukan nilai kecepatan potong yang optimal dapat diperoleh dengan menggunakan persamaan kecepatan potong maximum product dan minimum cost.namun untuk memperoleh nilai-nilai variable pada pemesinan tersebut, diperlukan data dari pemesinan seperti waktu pemesinan, biaya yang diperlukan meliputi benda kerja, mata pahat, mesin perkakas, upah buruh. Dan juga gaya pemotongan yang terjadi.

Berdasarkan hal tersebut, maka dilakukan penelitian ini untuk menentukan kecepatan potong yang optimal ketika melakukan proses pemotongan baja AISI 4140 yang berbentuk batangan (round bar). Dalam proses produksi, perhitungan biaya pemesinan merupakan suatu yang penting. Perhitungan biaya pemesinan melibatkan beberapa variabel yang terkait dengan proses pemesinan, Peralatan yang digunakan, energi listrik, biaya tenaga kerja, serta waktu produktif dan non produktif pada proses permesinan. Perubahan yang terjadi selama proses pemesinan memberi dampak terhadap perubahan kondisi pemesinan yang berlangsung dan tentunya akan memberi efek terhadap perhitungan biaya pemesinan. Untuk menentukan nilai cost per piece pada setiap benda kerja dengan variasi kecepatan potong (Vc) yang berbeda disampaikan dalam persamaan berikut [1]:

$\mathrm{Cu}=\mathrm{Cm}+\mathrm{Cplan}+\Sigma \mathrm{Cp}$

Dengan:

$\mathrm{Cu} \quad$ : Biaya total, Rp/produk

$\mathrm{Cm} \quad$ : Biaya material, Rp/produk

Cplan : Biaya persiapan/perencanaan produksi, Rp/produk

Cp : Biaya salah satu proses produksi, Rp/produk 
Biaya salah satu proses produksi

$\mathrm{Cp}=\mathrm{Cr}+\mathrm{Cm}+\mathrm{Ce}$

Dengan:

$\mathrm{Cr}$ : Biaya penyiapan \& peralatan, Rp/produk

$\mathrm{Cm}$ : Biaya permesinan, Rp/produk

$\mathrm{Ce}$ : Biaya pahat, Rp/produk

Biaya operasi

$\mathrm{Cm}=\mathrm{c}_{\mathrm{m}} / \mathrm{t}_{\mathrm{m}}$

Dengan:

$\mathrm{C}_{\mathrm{m}} \quad$ : Biaya operasi (mesin, operator, overhead) per satuan waktu, Rp/min

$t_{m} \quad$ : Waktu permesinan, min/produk

Waktu pemesinan [4]

$\mathrm{t}_{\mathrm{m}}=\mathrm{ta}+\mathrm{tc}+\mathrm{td} . \mathrm{tc} / \mathrm{T}$

Dengan:

ta : Waktu non produktif; min/produk

tc : Waktu pemotongan sesungguhnya, min/produk

$\mathrm{t}_{\mathrm{d}} \cdot \mathrm{t}_{\mathrm{c}} / \mathrm{T}$ : Waktu penggantian pahat yang dibagi rata untuk sejumlah produk yang dihasilkan sejak pahat yang dipasang sampai diganti karena aus

Waktu pemotongan sesungguhnya:

$\mathrm{tc}=\frac{\mathrm{l}_{\mathrm{t}}}{\mathrm{v}_{\mathrm{f}}}$ atau $\frac{\mathrm{l}_{\mathrm{t}}}{\mathrm{n.f}}$

Dengan:

$\mathrm{l}_{\mathrm{t}}=$ Panjang material benda kerja yang akan dilakukan proses pemesinan, $\mathrm{mm}$

$\mathrm{f}=$ Kecepatan makan, $\mathrm{mm} / \mathrm{min}$

Waktu non produktif:

$$
\mathrm{ta}=\mathrm{t}_{\mathrm{LW}}+\mathrm{t}_{\mathrm{AT}}+\mathrm{t}_{\mathrm{RT}}+\mathrm{t}_{\mathrm{UW}}+\frac{\mathrm{t}_{\mathrm{s}}}{\mathrm{n}_{\mathrm{l}}}
$$

Dengan:

ta : Waktu non produktif, min/produk

$t_{\text {LW }}:$ Waktu pemasangan benda kerja, min/produk

$t_{\mathrm{AT}}$ : Waktu penyiapan dari menggerakan pahat posisi semula sampai siap memotong, $\mathrm{mm} /$ produk

$\mathrm{t}_{\mathrm{RT}}$ : Waktu pengakhiran, min/produk

$t_{\text {Uw }}$ : Waktu pengambilan produk, min/produk

$\mathrm{t}_{\mathrm{s}} / \mathrm{n}_{1}$ : Waktu penyiapan mesin \&peralatan yang dibagi dengan jumlah produk, min/produk 
Biaya pahat

$\mathrm{Ce}=$ ce. $\mathrm{t}_{\mathrm{c}} / \mathrm{T}$

Dengan:

Ce : Biaya pahat, Rp/produk

$\mathrm{C}_{\mathrm{e}} \quad$ : Biaya pahat per mata potong, $\mathrm{Rp}$

$t_{c} / T$ : Sebagian dari umur pahat rasio antara waktu pemotong efektif $t_{c}$ dengan umur pahat (mata potong/produk)

Biaya mata pahat per mata potong [4]:

$$
c_{e}=\frac{c_{o t i}}{e}+\frac{c_{s h}}{r}+\left(c_{s} t_{s}\right)
$$

Dengan:

$\mathrm{C}_{\mathrm{e}} \quad$ : Biaya mata potong pahat, $\mathrm{Rp} /$ mata potong

$\mathrm{C}_{\text {oti }}$ : Harga sisipan karbida, Rp

e : Jumlah mata potong sisipan karbida

$\mathrm{C}_{\mathrm{sh}} \quad$ : Harga badan pahat pemegang sisipan, $\mathrm{Rp}$

$r$ : Jumlah pemakaian badan pahat sampai rusak, aus (500-1000x)

$\mathrm{C}_{\mathrm{s}} \mathrm{t}_{\mathrm{s}}$ : Biaya penyetelan pahat diluar mesin, $\mathrm{Rp} /$ mata potong

Untuk menentukan nilai production rate $\left(\mathrm{R}_{\mathrm{p}}\right)$ dari setiap benda kerja dengan variasi kecepatan potong yang berbeda digunakan persamaan:

$$
\mathrm{R}_{\mathrm{p}}=\frac{1}{\mathrm{t}_{\mathrm{m}}+\mathrm{t}_{\mathrm{a}}+\mathrm{t}_{\mathrm{c}}+\mathrm{t}_{\mathrm{e}}}, \text { produk } / \mathrm{min}
$$

\section{Dengan:}

tm : Waktu pemesinan, min

ta : Waktu untuk memasang \& mengeluarkan benda kerja, menjepit, dan semua kegiatan sebelum dan sesudah proses pemesinan, min

tc : Waktu yang terjadi pada kesalahan dalam pemotongan, min

te : Waktu pada saat mengatur mekanisme mesin dan perangkat kerja, min

Untuk menentukan nilai kekasaran permukan ( $\mathrm{Ra}$ ) digunakan persamaan [2]:

$\mathrm{R}_{\mathrm{a}}=2,95 \cdot \mathrm{f}^{0,7} \cdot \mathrm{r}^{-0,4} \cdot \mathrm{T}^{0,3}$

Dengan:

f : Gerak makan / feed rate $(\mathrm{mm} / \mathrm{rev})$

$\mathrm{r} \quad$ : Tool nose radius $(\mathrm{mm})$

$\mathrm{T} \quad$ : Cutting time (min)

Dalam menghitung kecepatan potong ekonomis (minimum cost), dipakai persamaan [2]:

$V_{c_{\text {min }}}=\frac{C_{v}}{\left[\left(\frac{1}{n-1}\right) \frac{\left(C_{w}+C_{d} \cdot t_{c}\right)}{C_{d}}\right]^{n}}$

Dengan:

$\mathrm{C}_{\mathrm{v}} \quad$ : Konstanta kecepatan potong yang berkerja dalam 1 menit 
$\mathrm{C}_{\mathrm{w}} \quad$ : Biaya pahat (dalam mata uang rupiah)

$\mathrm{C}_{\mathrm{d}}$ : Biaya pengoperasian seperti upah pekerja, mesin, dll. (Rp/min)

$\mathrm{t}_{\mathrm{c}} \quad$ : Waktu pemotongan (min)

$\mathrm{n} \quad$ : Eksponen umur pahat

Waktu pemotongan teoritikal dalam proses pembubutan dihitung dengan menggunakan persamaan berikut [5]:

$t_{c}=\frac{l_{t}}{V_{f}}$

Dengan:

$\mathrm{l}_{\mathrm{t}} \quad$ : Panjang permesinan $(\mathrm{mm})$

$\mathrm{V}_{\mathrm{f}} \quad$ : Kecepatan makan $(\mathrm{mm} / \mathrm{min})$

Kecepatan pemakanan dalam proses pembubutan digunakan rumus:

$V_{f}=f \times n$

Dengan:

f : Gerak makan $(\mathrm{mm} / \mathrm{r})$

$\mathrm{n} \quad$ : Putaran poros utama benda kerja $(\mathrm{r} / \mathrm{min})$

Untuk menghitung kecepatan potong maximum product digunakan persamaan [2]

$V_{c_{\max }}=\frac{C_{v}}{\left\{\left(\frac{1}{n-1}\right) t_{c}\right\}^{n}}$

Dengan:

$\mathrm{C}_{\mathrm{v}} \quad$ : Konstanta kecepatan potong yang berkerja dalam 1 menit

$\mathrm{C}_{\mathrm{d}}$ : Biaya pengoperasian seperti upah pekerja, mesin, dll. (Rp/min)

$\mathrm{t}_{\mathrm{c}} \quad$ : Waktu pemotongan (min)

$\mathrm{n} \quad$ : Eksponen umur pahat

Untuk setiap jenis benda kerja yang dibubut memerlukan suatu kombinasi parameter pemotongan yang sesuai agar produk yang dihasilkan memiliki kualitas yang baik dan waktu produksi yang relatif singkat dan tentunya biaya yang relatif rendah. Berdasarkan hal tersebut, maka penelitian ini dilakukan yang bertujuan untuk menghitung biaya pembubutan yang dipotong menggunakan mata pahat karbida CVD coating dan production rate logam baja AISI 4140 yang dibutuhkan untuk mendapatkan kecepatan potong optimal.

\section{METODE PENELITIAN}

Untuk mencapai objektif kajian terutama perhitungan biaya pemesinan dan jumlah produksi maksimum, maka diperlukan data waktu pemesinan dari variasi kecepatan pemotongan yang digunakan. Data tersebut diperoleh melalui experiment proses pembubutan benda kerja.

\section{Bahan}

Benda kerja yang digunakan Baja AISI 4140 round bar berdiameter $65 \mathrm{~mm}$ dan panjang 156 mm. Adapun benda kerja tersebut ditunjukkan pada Gambar 1. 

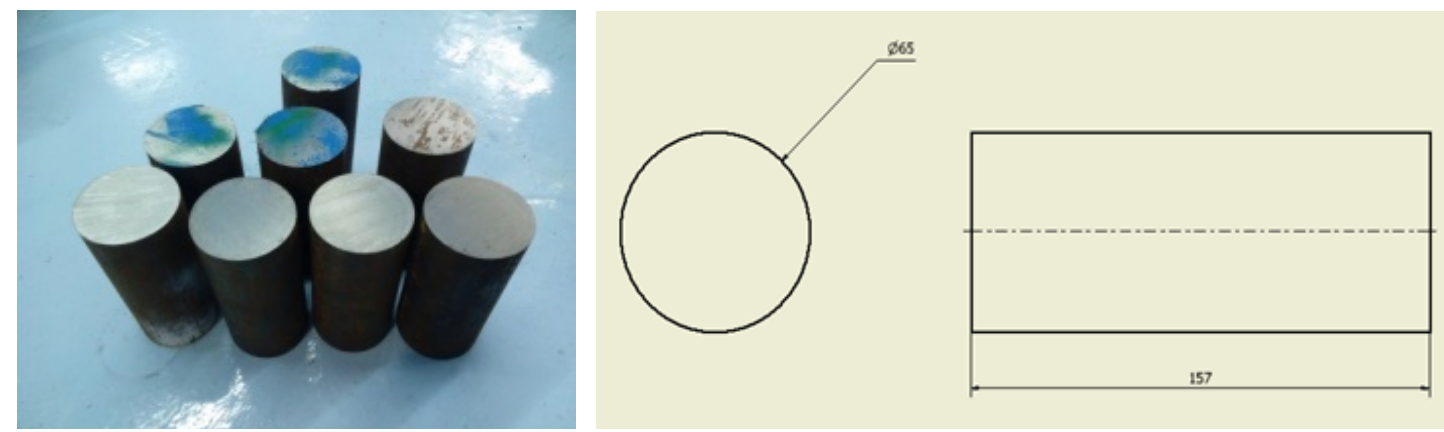

Gambar 1. Benda kerja AISI 4140

Bahan baja AISI 4340 memiliki unsur dan komposisi kimia sebagai berikut [6]:

Tabel 1. Komposisi kimia baja AISI 4340

\begin{tabular}{lc}
\hline \multicolumn{1}{c}{ Unsur Kimia } & Persentase (\%) \\
\hline Besi (Fe) & $96,785-97,77$ \\
Krom (Cr) & $0,8-1,1$ \\
Mangan (Mn) & $0,75-1,0$ \\
Karbon (C) & $0,38-0,43$ \\
Silikon (Si) & $0,15-0,30$ \\
Molybdenum (Mo) & $0,15-0,25$ \\
Sulfur (S) & 0,04 \\
Fosfor (F) & 0,035 \\
\hline
\end{tabular}

Sifat-sifat yang dimiliki bahan benda kerja tersebut antara lain [6]:

Tabel 2. Sifat-sifat material baja AISI 4340

\begin{tabular}{lc}
\hline \multicolumn{1}{c}{ Kekerasan } & $\mathbf{1 9 7} \mathrm{HB}$ \\
\hline Tensile Strength & $655 \mathrm{MPa}$ \\
Yield Strength & $415 \mathrm{MPa}$ \\
Elastic Module & $205 \mathrm{kN} / \mathrm{mm}^{2}\left(100^{\circ} \mathrm{C}\right)$ \\
Density & $7,85 \mathrm{Kg} / \mathrm{dm}^{3}$ \\
\hline
\end{tabular}

Tipe mata pahat karbida yang digunakan adalah TNMG 160404-MA yang dapat digunakan dalam proses pembubutan medium cutting sampai dengan finish cutting. Geometri dari jenis mata pahat tersebut disampaikan pada gambar berikut:
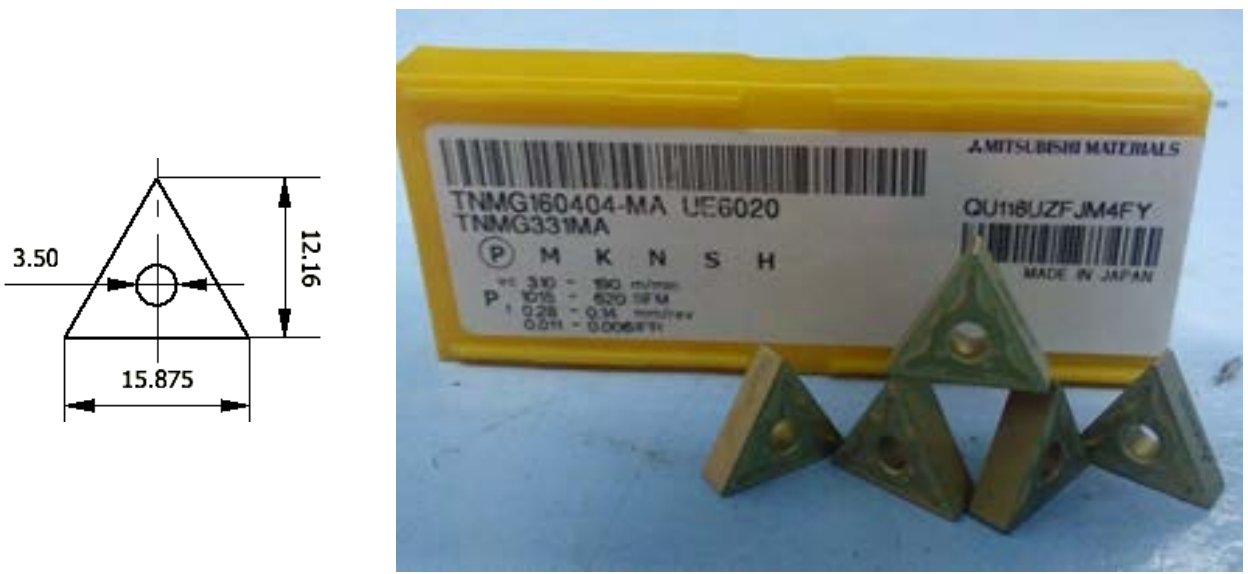

Gambar 2. Mata pahat karbida

Pemegang mata pahat yang digunakan adalah tipe PTGNR 2020 K16 sebagaimana ditunjukkan pada gambar berikut: 


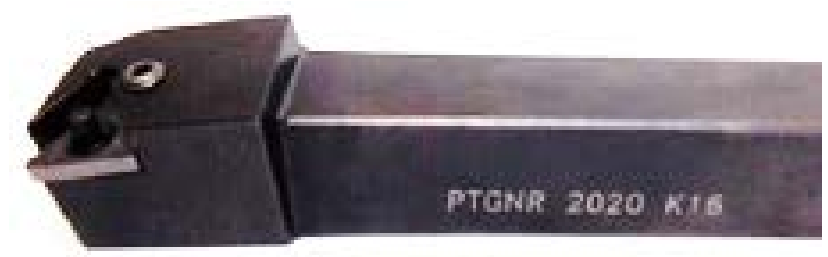

Gambar 3. Tool holder

\section{Peralatan}

Pengujian kemampuan pemotongan mata pahat dilakukan menggunakan mesin bubut CNC dengan spesifikasi sebagai berikut:

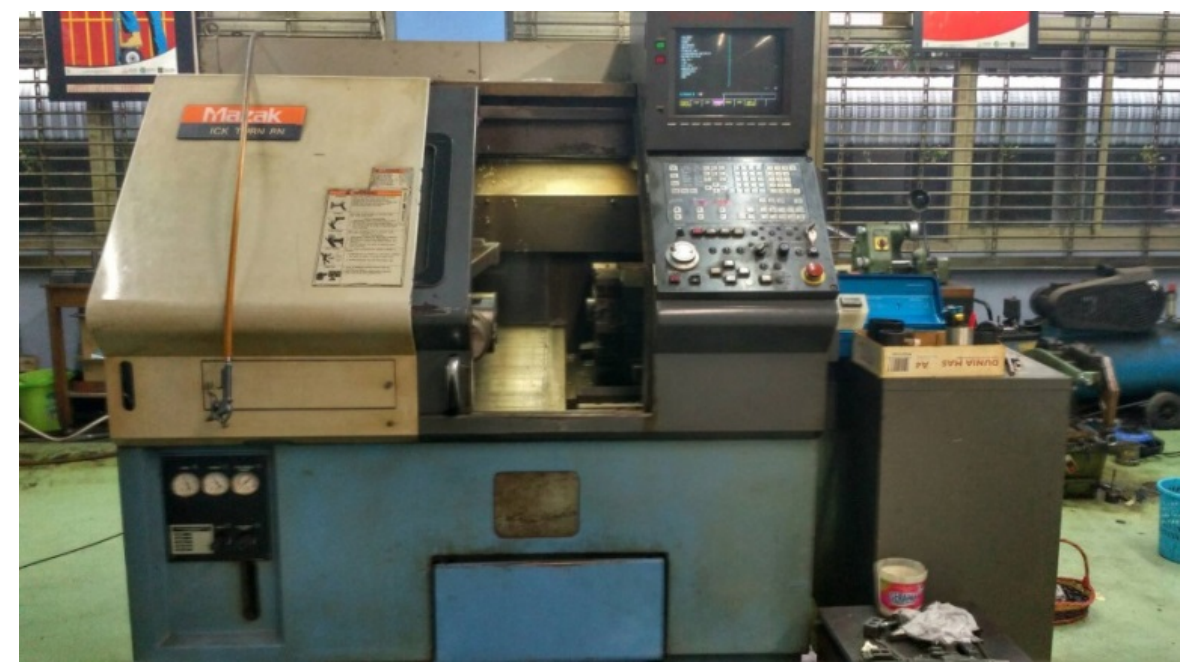

Gambar 4. Mesin bubut CNC Mazak Type Quick Turn 8N

Alat ukur kekasaran permukaan surface tester Mitutoyo Surftest 211 sebagaimana diitunjukkan pada gambar di bawah ini.

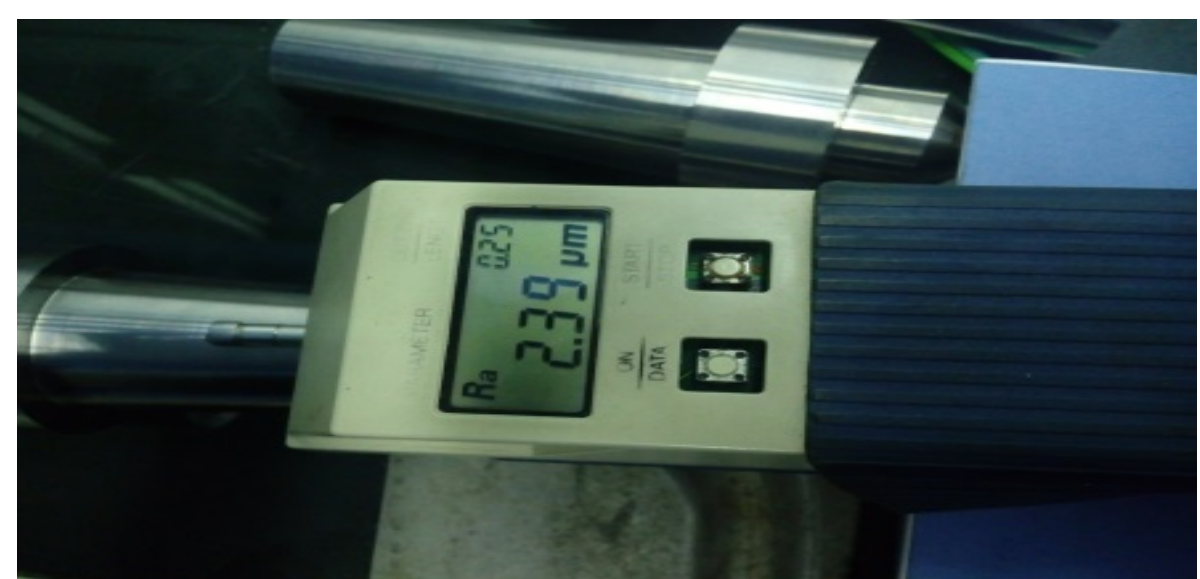

Gambar 5. Alat ukur kekasaran permukaan (surface tester)

\section{Prosedur Pengerjaan}

Prosedur penelitian yang dilakukan dalam kajian ini disampaikan pada Gambar: 


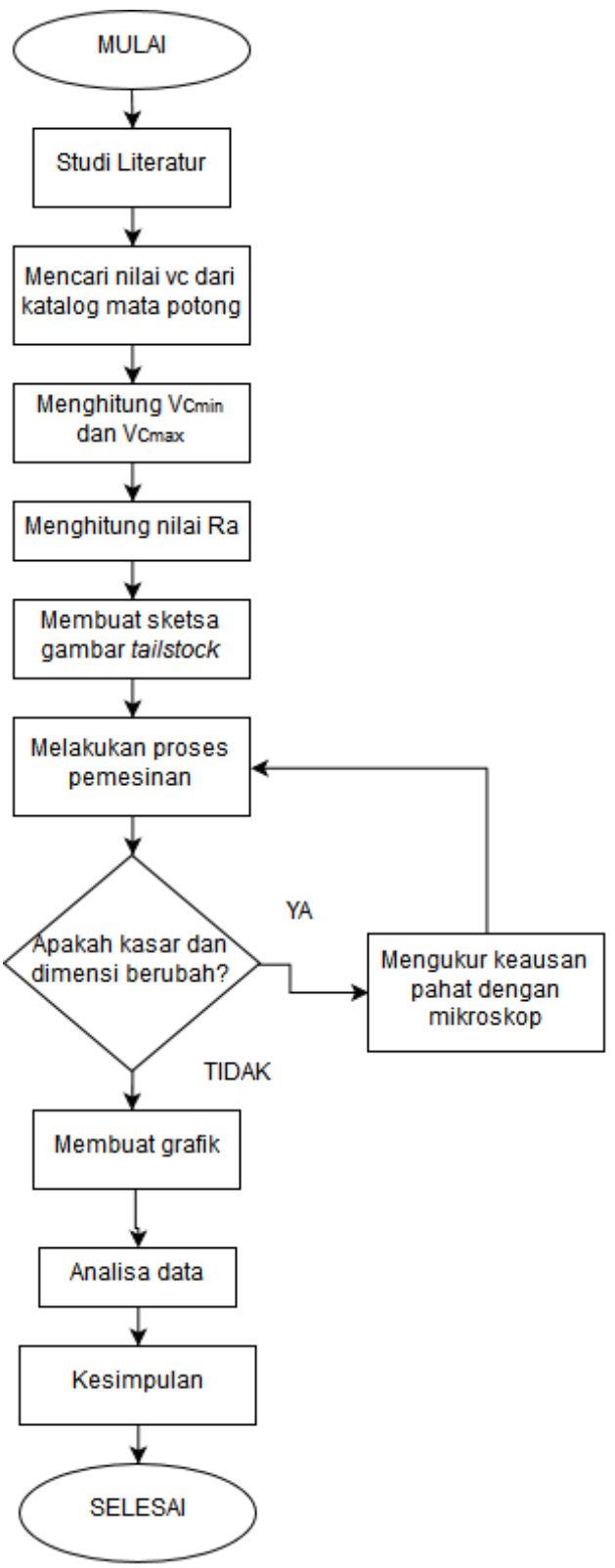

Gambar 6. Diagram alir penelitian

\section{HASIL DAN PEMBAHASAN}

Pada proses pemesinan objek yang dibubut berupa bentuk tailstock pengerjaan dilakukan secara bertahap dikarenakan mata pahat tipe TNMG yang berbentuk segitiga yang tidak bisa dalam membentuk grooving sehingga proses tersebut dilakukan dalam 2 tahap yaitu depan dan belakang.

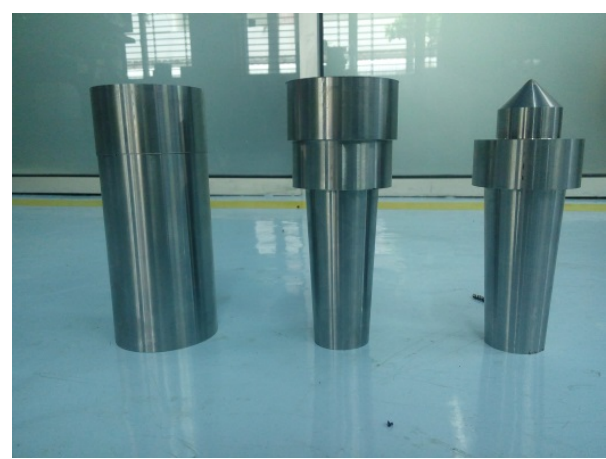

Gambar 7. Tahapan pembentukan tailstock 
Pada proses pemesinan ini data yang diperoleh merupakan waktu pemesinan yang terjadi dari variasi kecepatan pemotongan.

Setelah diperoleh data proses pemesinan yaitu waktu pemesinan $\left(\mathrm{t}_{\mathrm{m}}\right)$, maka selanjutnya dilakukan perhitungan production rate (Rp) dan perhitungan cost per product (Ce) pada masingmasing benda kerja dengan variasi nilai kecepatan potong.Adapun hasil yang diperoleh grafik pengaruh kecepatan pemotongan terhadap production rate disampaikan pada Gambar berikut:

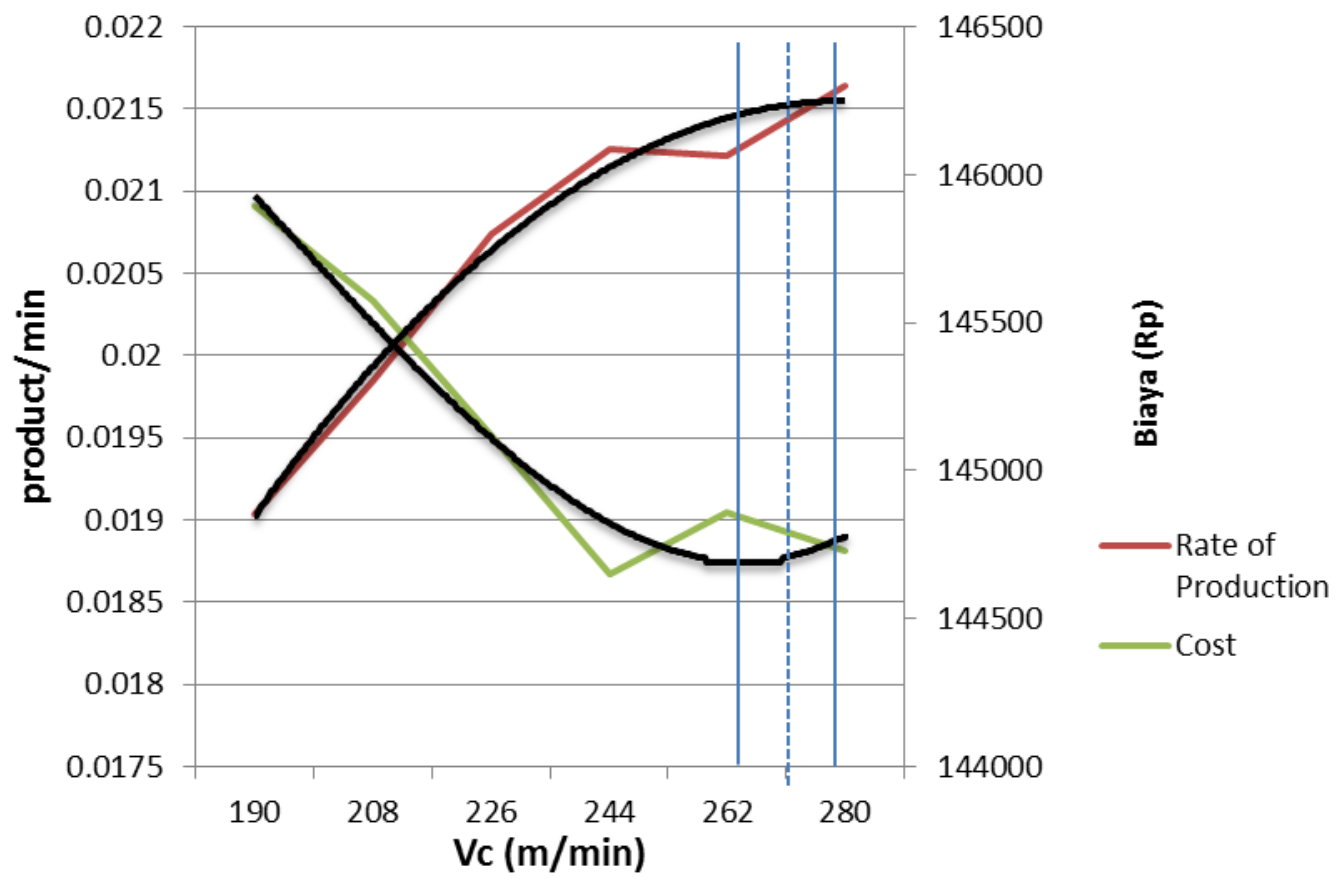

Gambar 8. Grafik kecepatan potong optimal

Dari hasil pengamatan pada proses pemesinan, menunjukkan bahwa peningkatan kecepatan pemotongan memberi efek terhadap waktu pemesinan, dimana waktu potong menjadi lebih singkat, dan hal ini tentunya secara signifikan memberi pengaruh dalam perhitungan biaya produksi karena terjadi pengurangan penggunaan energi dan gaya pemotongan yang digunakan. Peningkatan kecepatan pemotongan memberi efek terhadap jumlah produksi yang dihasilkan hal ini dapat dilihat pada gambar 8. Dari kedua kurva di atas, dapat ditentukan titik nilai maksimal pada perhitungan produksi dan titik nilai minimal pada perhitungan biaya pemesinan. Sehingga diperoleh nilai kecepatan potong berdasarkan kurva tersebut adalah sebesar 269 m/min.

\section{SIMPULAN} berikut:

Setelah dilakukan analisis dari data yang diperoleh maka dapat dibuat kesimpulan sebagai

1. Peningkatan kecepatan pemotongan memberi pengaruh terhadap peningkatan jumlah produksi, sedangkan untuk perhitungan biaya pemesinan mengalami penurunan.

2. Waktu pemesinan memberi pengaruh yang signifikan terhadap perubahan jumlah produksi dan biaya pemesinan.

3. Kecepatan pemotongan optimal ( $\left(\mathrm{Vc}_{\mathrm{opt}}\right)$ sebesar $269 \mathrm{~m} / \mathrm{min}$ dengan biaya pemesinan sebesar Rp. 14.821.

\section{DAFTAR PUSTAKA}

[1]. Rochim, Taufiq (1985). Proses Permesinan. Bandung: Jurusan Teknik Mesin, Fakultas Teknik Industri-Institut Teknologi Bandung.

[2]. Halevi, Gideon (1995). Principles of Process Planning, London: Chapman \& Hall, 
[3]. Mayer, Vernice (2006). Annual Book of ASTM Standards 2006, West Conshohocken,

[4]. Lubis, Sobron. Y. (2013). Analisa Perhitungan Biaya Pembubutan Baja AISI 4340 Menggunakan Pahat Keramik, Jurnal Kajian Teknologi, Fakultas Teknik Universitas Tarumanagara. ISSN 1411-2698.

[5]. Knight, J. (1995). Improved Model to Determine Tool Life and Optimum Cutting Speed for Minimum Machining Cost. Advanced in Manufacturing Technology IX. Proceeding of the Eleventh National Conference on Manufacturing Research. Leicester, 12 -14 September 1995: De Montfort University.

[6]. Birkby, Ian. (2015). AZOM Material Encyclopedia. Available:

http://www.azom.com/article.aspx?ArticleID=6769 